\title{
Predicting reattendance to the second round of the Maltese national breast screening programme: an analytical descriptive study
}

\author{
Danika Marmarà ${ }^{1,2^{*}}$ (D) Vincent Marmarà ${ }^{3}$ and Gill Hubbard ${ }^{4}$
}

\begin{abstract}
Background: A range of barriers influence women's uptake to a first breast screening invitation. Few studies however, have examined factors associated with second screening uptake. This study follows Maltese women to explore predictors and behaviours to re-attendance, and to determine if uptake of first invitation to the Maltese Breast Screening Programme (MBSP) is a significant predictor of second screening uptake.

Methods: A prospective study was conducted to determine factors associated with re-attendance for 100 women invited to the second MBSP round. Records of women's second attendance to the MBSP were extracted in January 2016 from the MBSP database. Data were analyzed using chi-square tests, Independent Samples t-test, Mann Whitney test, Shapiro Wilk test and logistic regression.

Results: There were no significant associations for sociodemographic or health status variables with second screening uptake ( $p>0.05)$, except breast condition (Fisher's exact test, $p=0.046)$. Non-attendees at second screening were most unsure of screening frequency recommendations $(x 2=9.580, p=0.048)$. Attendees were more likely to perceive their susceptibility to breast cancer ( $p=0.041)$, believed breast cancer to be life changing $(p=0.011)$ and considered cues to action to aid attendance $(p=0.028)$. Non-attendees were in stronger agreement on mammography pain $(p=0.008)$ and were less likely to consider cues to action (15.4\% non-attendees vs $1.4 \%$ attendees) ( $p=0.017$ respectively). 'Perceived barriers', 'breast cancer identity', 'causes' and 'consequences' were found to be significant predictors of second screening uptake, with 'perceived barriers' being the strongest. The inclusion of illness perception items improved the regression model's accuracy in predicting non-attendance to the second screening round (84.6\% vs $30.8 \%)$. First screening uptake was found to be a significant predictor of subsequent uptake $(\mathrm{OR}=0.102 ; 95 \% \mathrm{Cl}=0.037$, $0.283 ; p=0.000$ ).

Conclusions: Interventions to increase uptake should target first invitees since attending for the first time is a strong predictor of uptake to the second cycle. Further research is required given the small sample. Particular attention should be paid to women who did not respond to their first invite or are unsure or reluctant participants initially.
\end{abstract}

Keywords: Breast cancer, Screening, Mammography, Attendance, Reattendance, Second invitation

\footnotetext{
* Correspondence: attard.danika@gmail.com

${ }^{1}$ Faculty of Health Sciences, University of Stirling, School of Health Sciences,

Room E9, Pathfoot, Stirling FK9 4LA, Scotland

${ }^{2}$ Cancer Care Pathways Directorate, Sir Anthony Mamo Oncology Centre

Level -1, Dun Karm Street, Msida MSD 2090, Malta

Full list of author information is available at the end of the article
}

(c) The Author(s). 2019 Open Access This article is distributed under the terms of the Creative Commons Attribution 4.0 International License (http://creativecommons.org/licenses/by/4.0/) which permits unrestricted use, distribution, and reproduction in any medium, provided you give appropriate credit to the original author(s) and the source, provide a link to the Creative Commons license, and indicate if changes were made. The Creative Commons Public Domain Dedication waiver (http://creativecommons.org/publicdomain/zero/1.0/) applies to the data made available in this article, unless otherwise stated. 


\section{Background}

Breast cancer continues to be a major cause of female morbidity and mortality worldwide [1]. Regular breast screening (BS) for breast cancer (BC) could lead to a $25-30 \%$ reduction in mortality rates in the population of women invited for screening [2]. This evidence led to the implementation of screening programmes across Europe based on the EU Council recommendations, which recommend biennial screening mammography in average-risk women aged 50-69 years [3]. A Maltese breast screening programme (MBSP) was set up in Malta in 2009 to screen women (aged 50 - 60 years) through mammography every 3 years [4], aiming gradual expansion to reach women until the age of 69 years while reducing the screening time interval as in other countries [5]. In 2015, this age cohort (50-60 years) was in its second BS round.

Breast screening uptake is defined as "the proportion of women invited who attend for screening within 6 months of their invitation" ([6], p.1). In Malta, the overall attendance rate was below the acceptable target of $70 \%$ in the first BS round [7]. Similarly, substantial variation in BC uptake exists across other countries [1]. An important factor that merits exploration includes regular screening adherence, because of its significant impact on morbidity and mortality reductions $[8,9]$. Detecting $\mathrm{BC}$ early is not ensured by a one-off BS attendance [10], but on the consistency of attendance in line with recommended time intervals [11]. The literature suggests that previous mammography use is highly associated with future use [12] because women believe in the effectiveness of screening which in turn increases their intentions to go for screening, resulting in their adherence to subsequent screens [13]. An earlier study by Cockburn and colleagues [14] found that those having weakest intentions to attend for their first screening are less likely to attend for their second screening $(\mathrm{OR}=0.44, \mathrm{CI} 0.23,0.85)$. Therefore, it has been suggested that programs should focus on reaching those who have underutilized mammography in their past [12] as this would feed into attendance in subsequent BS invitation rounds. Nonetheless, many studies have focused on the reasons for one-time screening rather than subsequent use $[9,15]$ and limited studies have sought to specifically explore predictors of uptake to second round BS invitations [14, 16, 17]. In a comparative study of 200 re-attenders and 200 non-re-attenders for second triennial National Breast Screening Programme appointments in Nottingham [10], the 200 women who failed to accept their invitation implicated their negative initial screening experience in their decision, with $41 \%$ implicating pain, $6 \%$ stress and $3 \%$ embarrassment.

To our knowledge, no research yet exists on women's reattendance at the MBSP or on screening predictors to the second BS round in Malta. In 2017, we reported on first screening uptake of the MBSP [4]. We found that Health Belief Model (HBM) constructs were the strongest predictors of uptake of first invitation to the MBSP, though the inclusion of illness representation dimensions improved the predictive accuracy for non-attendance. In the present study, we follow a sub-sample of Maltese women with three main objectives: (1) to determine their re-attendance at the second BS invitation round; (2) to explore whether sociodemographic factors, health status, knowledge, health beliefs and illness perceptions are significant predictors of second BS uptake; and (3) to determine if uptake of first invitation to attend the MBSP is a significant predictor of uptake to the second invitation in Malta.

\section{Theoretical framework}

BS behaviour is influenced by a number of factors, including health beliefs [8], illness representations [8], knowledge of BC and BS [4], socio-demographic factors [4], and health status (medical factors) [8]. These factors were found to influence BS attendance in the first invitation round in Malta [4]. The Health Belief Model (HBM) was used as a theoretical framework for this study, due to its application in myriad preventive health behaviours, including BS [8, 18-20]. The HBM consists of six main variables (constructs), namely perceived susceptibility, perceived severity, perceived benefits, perceived barriers, cue to action, and self-efficacy [19]. These variables play an important role in an individual's perception about BS, such that women are more likely to perform BS if they feel susceptible to $\mathrm{BC}$ or the risks of contracting $\mathrm{BC}$ (perceived susceptibility), believe in the seriousness and consequences of the disease (perceived severity), perceive more benefits than barriers from undergoing mammography, have higher confidence for obtaining mammography, and take heed in cues to action [19]. Based on the HBM, women's perceptions about $\mathrm{BC}$ are derived from their knowledge and perceptions about the disease, which predicts whether women will attend for mammography [18]. However, the HBM does not include the impact of emotions to predict BS behaviours, which is why the Common-Sense Model (CSM) [20], also used to explain BS behaviour in a small number of studies [8, 21-25], was utilised in this study. The CSM considers the cognitive and emotional representations of a health threat $[8,26,27]$ and guides subsequent coping behaviour [28]. Illness perceptions comprise the following constructs: $B C$ identity, cause, cancer timeline (acute/chronic, cyclical), consequences, personal and treatment control, illness coherence and emotional representations. [8, 21]. 


\section{Methods}

\section{Study design and setting}

The full details of the methods are described in detail in our prior paper [4]. This prospective study was conducted in Malta in January 2016 to determine factors associated with the second BS cycle.

\section{Participants}

Of the 404 women surveyed between June and September 2015 about their first BS attendance [4], 100 women were identified in January 2016 to have subsequently been invited to the second round. These 100 women were a sub-sample of participants of our larger study [4] who had received an invitation to attend both the first and second MBSP round. Description and characteristics of the larger sample $(n=404)$ are found in the previous study [4].

\section{Measures}

To predict reattendance, we used our previously constructed 121-item questionnaire based on Champion's Health Belief Model Scale (CHBMS-MS) and the Revised Illness Perception Questionnaire (IPQ-R). The full details of its translation, adaptation and pilot-testing among Maltese women have been described in detail in our prior published paper [29].

\section{Variable definitions}

A second invitation was defined as the second (subsequent) time a woman is invited to the MBSP and either attends or does not attend for the mammogram. Women were considered eligible in this study if their scheduled appointment date had elapsed for their second BS invitation and they had not informed the unit to reschedule their mammography invitation. A screening invitation is posted to the client approximately 1 month before the scheduled mammography date. Hence, those women invited to the second BS round and awaiting their scheduled day for mammography screening were not considered in this study.

\section{Data analysis}

Several statistical tests were used to analyse the differences between attendance or non-attendance to the second MBSP invitation. Chi-square test was used to test for association between two categorical variables (e.g. attendance against women's knowledge of the breast screening frequency); however, Fisher's exact test was used when the assumptions of the Chi-Square test were violated. The Shapiro-Wilk test was used to test for normality of all construct variables. Furthermore, the following tests were used throughout the analysis: the independent samples $\mathrm{t}$-test and the non-parametric Mann-Whitney test. Significant predictors for re-attendance were determined through the binary logistic regression.
Hence, several models were developed (using different constructs and variables) to predict attendance and non-attendance to the second MBSP invitation. The 'backward-elimination' was applied to exclude any non-significant variables from the latter models and the final output included the unstandardized coefficients, standard error, the Wald value, $p$-values, Odds Ratios (ORs) and $95 \%$ confidence intervals (95\% CIs). The data was analyzed using SPSS version 21 under the guidance of an expert statistician. A $P$-value of $<0.05$ was considered statistically significant (Table 1).

\section{Results}

\section{Sample characteristics}

Table 1 presents the sample characteristics $(n=100)$. At the time of the second screening cycle, women were aged between 53 and 63 years with a mean of 58.63 years ( $\pm 2.63 \mathrm{SD}$ (standard deviation)).

From the 100 women invited to the second screening round (Fig. 1), nearly three-quarters of this sample (74\%; $n=74$ ) attended the second screening round; of these, $83.8 \%(n=62)$ had responded to their first invitation while $16.2 \%(n=12)$ had not attended the first screening round. Over a quarter of our sample $(26 \% ; n=26)$ did not attend the second screening round; of these, $34.6 \%$ $(n=9)$ had attended the first screening cycle while $65.4 \%(n=17)$ had not responded to their first invitation. Women who attended their first invitation were more likely to sustain screening mammography adherence than non-attendees $\left(X^{2}=22.6, p<0.001\right)$.

\section{Associations between psychosocial factors, and attendance and non-attendance to a second BS invitation}

Similar to the analysis carried out in our previous papers to analyse the associations between attendees and non-attendees in relation to lifetime mammography practices [30] and timely adherence [31], the following analysis focused on the associations between attendees and non-attendees to a second BS invitation.

\section{Sociodemographic factors and health status}

There was a significant association between breast condition (lumps or cysts but not $\mathrm{BC}$ ) and second screening uptake (Fisher's exact test applied: $p=0.046$ ), whereby from those who attended their second invitation, $15.1 \%$ had a breast condition, whereas from among non-attendees, $34.6 \%$ had a breast condition. There were no significant associations for other sociodemographic or health status variables $(p>0.05)$.

\section{Knowledge}

There was a significant association between knowledge about recommended frequency for attending BS; women 
Table 1 Sample Characteristics $(n=100)$

\begin{tabular}{|c|c|c|c|c|}
\hline Characteristics & Mean & SD & $\mathrm{N}$ & $\%$ \\
\hline Age (year) & 58.63 & 2.63 & & \\
\hline \multicolumn{5}{|l|}{ Education level } \\
\hline Primary level & & & 26 & 26.0 \\
\hline Secondary level & & & 68 & 68.0 \\
\hline Tertiary level & & & 6 & 6.0 \\
\hline \multicolumn{5}{|l|}{ Occupation } \\
\hline Pensioner & & & 4 & 4.0 \\
\hline Housewife & & & 78 & 78.0 \\
\hline Employee & & & 18 & 18.0 \\
\hline \multicolumn{5}{|l|}{ Status } \\
\hline Single & & & 4 & 4.0 \\
\hline Married & & & 85 & 85.0 \\
\hline Separated/Divorced & & & 5 & 5.0 \\
\hline Widowed & & & 6 & 6.0 \\
\hline \multicolumn{5}{|l|}{ Family income } \\
\hline Less than $€ 10,737$ & & & 28 & 28.0 \\
\hline$€ 10,737-€ 16,113$ & & & 32 & 32.0 \\
\hline$€ 16,114-€ 23,563$ & & & 8 & 8.0 \\
\hline$€ 23,564-€ 33,966$ & & & 2 & 2.0 \\
\hline Greater than $€ 33,966$ & & & 2 & 2.0 \\
\hline Prefer not to say & & & 30 & 30.0 \\
\hline \multicolumn{5}{|l|}{ Own a car } \\
\hline Yes & & & 78 & 78.0 \\
\hline No & & & 22 & 22.0 \\
\hline \multicolumn{5}{|l|}{ Drive } \\
\hline Yes & & & 46 & 46.0 \\
\hline No & & & 54 & 54.0 \\
\hline \multicolumn{5}{|l|}{ Any illness, disability or condition } \\
\hline Yes & & & 58 & 58.0 \\
\hline No & & & 42 & 42.0 \\
\hline \multicolumn{5}{|l|}{ Family physician (GP) } \\
\hline Yes & & & 92 & 92.0 \\
\hline No & & & 8 & 8.0 \\
\hline \multicolumn{5}{|l|}{ Frequency of GP visit } \\
\hline Only when I have a problem & & & 80 & 80.0 \\
\hline Once a month & & & 5 & 5.0 \\
\hline More than once a year & & & 7 & 7.0 \\
\hline Missing & & & 8 & 8.0 \\
\hline \multicolumn{5}{|l|}{ Lumpy breasts } \\
\hline Yes & & & 9 & 9.0 \\
\hline No & & & 91 & 91.0 \\
\hline \multicolumn{5}{|c|}{ Relatives or close friends had cancer } \\
\hline Yes & & & 89 & 89.0 \\
\hline No & & & 9 & 9.0 \\
\hline Prefer not to say & & & 2 & 2.0 \\
\hline
\end{tabular}

who did not attend the second screening invitation were most unsure of the recommended frequency $\left(\chi^{2}=9.580\right.$, $p=0.048)$.

\section{Health beliefs}

No statistical significance was found for the majority of the HBM constructs, except for 5 items (Table 2) as follows: $25.7 \%$ of women who attended the second round strongly disagreed with the statement: 'there is no is possibility of getting breast cancer' as opposed to $11.5 \%$ of non-attendees $(p=0.041)$, while $23.1 \%$ of non-attendees were undecided. Attendees considered more strongly than non-attendees (41.9\% vs $19.2 \%)$ that they would sustain mammography adherence if their GP advised them to attend $(p=0.028)$. Non-attendees were in stronger agreement than attendees $(11.5 \%$ vs $0.0 \%)$ that mammography is painful or uncomfortable $(p=0.008)$. Non-attendance at the second invitation round was more likely for women who considered reminder letters, reminder phone calls and text messages not to be of help (15.4\% non-attendees vs $1.4 \%$ attendees $) \quad(p=0.017$ respectively).

\section{Illness perceptions}

No statistical significance was found for all illness perception items except for one variable (Table 3): those who attended the second screening round agreed more strongly than non-attendees $(39.2 \%$ vs $7.7 \%)$ that their whole life would change if breast cancer occurred $(p=$ 0.011).

\section{Differences between attendees and non-attendees}

We further explored health beliefs and illness perceptions as 'constructs' and which of these constructs were statistically significant with second BS uptake. Table 4 shows the relationship between all 14 constructs respectively (perceived susceptibility, perceived benefits, perceived barriers, cues to action, self-efficacy, breast cancer identity, causes of breast cancer, cancer timeline: acutel chronic, cancer timeline: cyclical, consequences, personal control, treatment control, illness coherence, emotional representations), and attendance and non-attendance to second BS round.

The 'perceived barrier' construct was the only statistically significant variable that described the variance between attendees and non-attendees.

\section{Predictors of attendance and non-attendance to the second screening round}

Similar to the analyses carried out in our previous paper to predict lifetime mammography attendance in Malta [30], the following analyses focused on predicting attendance and non-attendance to the second BS invitation. The most significant variables for all logistic 


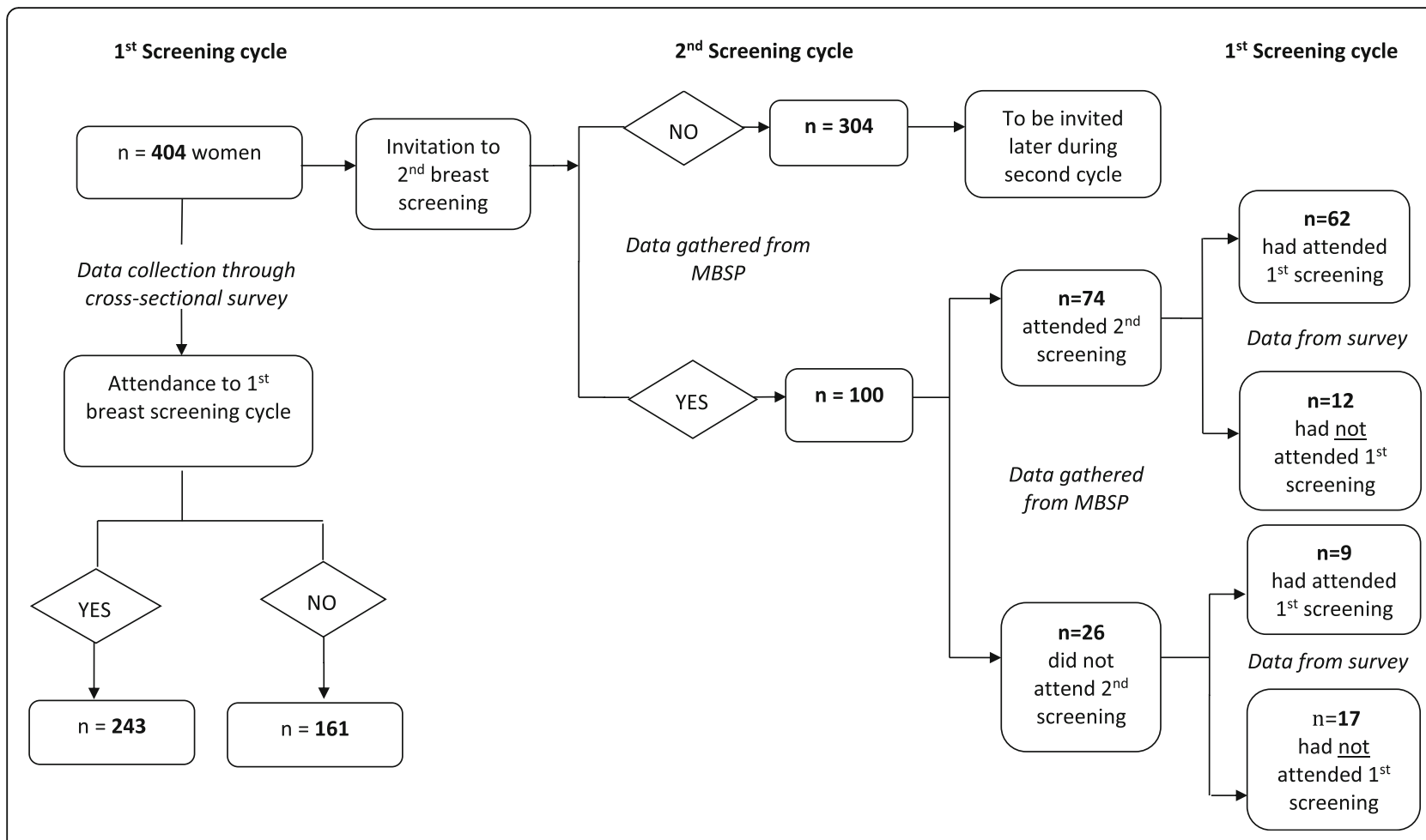

Fig. 1 First and second breast screening invitation pathway

regression models are presented in Table 5. Logistic regression models 1 and 2 incorporated all items related to demographic and health status variables respectively, though none were found to be significant predictors of second BS uptake.

Models 3 to 7 include the psychosocial variables. Model 3 incorporated all HBM variables, of which three variables were found to be good predictors of second BS uptake: 'there is no possibility of getting breast cancer,' 'fear of the unknown procedure', and 'GP advice to attend' (Table 5). For this model, attendance was predicted with an accuracy of $93.2 \%$ and non-attendance with $30.8 \%$ accuracy. When removing 'fear of the unknown procedure' from the model, the accuracy decreased from 30.8 to $19.2 \%$ and hence was retained even though $p>0.05$.

Model 4 included all IPQ-R variables, of which four IPQ-R variables were found to be good predictors: 'breast swelling, dimpling, redness or soreness of the skin', 'diet', 'altered immunity', and 'if you had BC, your whole life would change' (Table 5). The accuracy for this model was $89.2 \%$ for attendance and $69.2 \%$ for non-attendance.

Model 5 focused on the significant variables found in model 3 and 4 together; i.e. on 12 variables (five Health Beliefs and seven Illness Perception variables). The final model (Model 5) retained the same significant predictors as in Model 4, excluding the HBM variables, hence showing that illness perceptions are important predictors for second BS uptake. The model accuracy, when combining both scores, was identical to that of Model 4 , predicting attendance by $89.2 \%$ and non-attendance by $69.2 \%$.

Model 6 incorporated all individual Health Belief and Illness Perception items, of which 14 variables were significantly different. However, the latter variables made this model more complex due to the large number of predictors. The model accuracy improved substantially to $95.9 \%$ for attendees and $84.6 \%$ accuracy for non-attendees. The model accuracy decreased from 84.6 to $76.9 \%$ when the following variables were removed from the model: 'if you find a lump through a mammogram, the treatment for breast cancer may not be as bad' and 'having a mammogram will decrease your chances of dying from breast cancer'. Hence, the latter variables were retained even though $p>0.05$.

A logistic regression model (Model 7) was constructed with all 14 constructs (i.e. HBM and IPQ-R as constructs not individual items). The following constructs were the most significant predictors of second screening uptake: 'perceived barriers,' 'breast cancer identity', 'causes of breast cancer' and 'consequences'. The 'perceived barriers' construct was found to be the strongest predictor. However, non-attendance was predicted with an accuracy of $30.0 \%$, which is inferior when compared to Models 5 and 6 (69.2\%). Moreover, when removing the 
Table 2 Comparison of Health Beliefs between attendees and non-attendees

\begin{tabular}{|c|c|c|c|c|c|c|c|c|}
\hline \multirow{2}{*}{$\begin{array}{l}\text { Attendance to the second breast screening invitation } \\
\text { Health Beliefs }\end{array}$} & \multicolumn{2}{|l|}{ Yes } & \multicolumn{2}{|l|}{ No } & \multicolumn{2}{|l|}{ Total } & \multicolumn{2}{|c|}{$\begin{array}{l}\text { Chi-Square } \\
\text { test }^{\mathrm{a}}\end{array}$} \\
\hline & Mean & SD & Mean & SD & Mean & SD & $x^{2}$ & $\begin{array}{l}p^{-} \\
\text {value }\end{array}$ \\
\hline There is no possibility of getting breast cancer $(r)$ & 1.8 & 0.6 & 2.2 & 0.7 & 1.9 & 0.6 & 0.3 & $0.041^{*}$ \\
\hline Your chances of getting breast cancer are high & 3.6 & 0.7 & 3.5 & 0.7 & 3.6 & 0.7 & 1.1 & 0.789 \\
\hline There may be the possibility of developing breast cancer in your lifetime & 4.0 & 0.3 & 3.9 & 0.4 & 4.0 & 0.3 & 3.8 & 0.147 \\
\hline When you get a mammogram, you feel good about yourself & 4.0 & 0.3 & 3.9 & 0.5 & 4.0 & 0.4 & 6.5 & 0.088 \\
\hline When you get a mammogram, you do not worry as much about breast cancer & 3.8 & 0.7 & 3.7 & 0.7 & 3.8 & 0.7 & 1.2 & 0.759 \\
\hline Having a mammogram will help you find lumps early in your breasts & 4.2 & 0.5 & 4.1 & 0.5 & 4.2 & 0.5 & 3.3 & 0.355 \\
\hline If you find a lump through a mammogram, the treatment for breast cancer may not be as bad & 4.0 & 0.4 & 4.0 & 0.2 & 4.0 & 0.3 & 1.2 & 0.750 \\
\hline Having a mammogram will decrease your chances of dying from breast cancer & 4.0 & 0.4 & 3.9 & 0.4 & 4.0 & 0.4 & 4.3 & 0.227 \\
\hline $\begin{array}{l}\text { Having a mammogram will help you find a lump before it can be felt by yourself or a health } \\
\text { professional }\end{array}$ & 4.0 & 0.4 & 3.9 & 0.4 & 4.0 & 0.4 & 3.3 & 0.344 \\
\hline Having a routine mammogram would make you anxious about breast cancer & 2.7 & 1.0 & 3.0 & 1.1 & 2.8 & 1.0 & 1.6 & 0.449 \\
\hline Having a routine mammogram would make you worry & 2.7 & 1.0 & 2.9 & 1.1 & 2.7 & 1.0 & 1.5 & 0.685 \\
\hline You fear having a mammogram because you might find out that something is wrong & 2.8 & 1.1 & 3.2 & 1.2 & 2.9 & 1.1 & 6.2 & 0.103 \\
\hline You fear having a mammogram because you do not know the procedure or what to expect & 2.1 & 0.5 & 2.4 & 0.8 & 2.2 & 0.6 & 4.8 & 0.092 \\
\hline You fear having a mammogram because you know someone (family or friend) with breast cancer & 2.6 & 1.1 & 2.7 & 1.2 & 2.6 & 1.1 & 0.6 & 0.907 \\
\hline It is embarrassing for you to have a mammogram & 2.3 & 0.8 & 2.4 & 0.9 & 2.4 & 0.8 & 0.5 & 0.779 \\
\hline Undergoing mammography will be painful or uncomfortable & 3.2 & 1.0 & 3.3 & 1.1 & 3.2 & 1.0 & 11.9 & $0.008^{*}$ \\
\hline Having a mammogram is time consuming & 1.3 & 0.5 & 1.3 & 0.7 & 1.3 & 0.5 & 3.8 & 0.153 \\
\hline You are discontent with Breast Screening personnel as they have been rude to you & 1.1 & 0.4 & $\mathrm{n} / \mathrm{a}$ & $\begin{array}{l}\mathrm{n} / \\
\mathrm{a}\end{array}$ & 1.1 & 0.4 & $\mathrm{n} / \mathrm{a}$ & $\mathrm{n} / \mathrm{a}$ \\
\hline You have fear or distrust in the medical team & 1.7 & 0.8 & 2.0 & 0.8 & 1.8 & 0.8 & 4.7 & 0.094 \\
\hline Having a mammogram would expose you to unnecessary radiation & 2.2 & 0.6 & 2.4 & 0.8 & 2.3 & 0.7 & 1.6 & 0.652 \\
\hline You have too many other problems in your life than to get a mammogram done & 1.7 & 0.6 & 1.8 & 0.7 & 1.7 & 0.6 & 0.7 & 0.699 \\
\hline You are not old enough to have a mammogram periodically & 1.8 & 0.4 & 1.8 & 0.4 & 1.8 & 0.4 & 0.9 & 0.344 \\
\hline If your GP advises you to attend for a mammogram, you will attend & 4.4 & 0.5 & 4.1 & 0.6 & 4.3 & 0.6 & 9.1 & $0.028^{*}$ \\
\hline If your relatives or friends advise you to attend for a mammogram, you will attend & 3.6 & 0.9 & 3.3 & 1.0 & 3.5 & 0.9 & 1.9 & 0.586 \\
\hline If someone close to you has been diagnosed with breast cancer, you will attend for a mammogram & 4.3 & 0.9 & 4.2 & 0.9 & 4.3 & 0.9 & 0.9 & 0.826 \\
\hline $\begin{array}{l}\text { Hearing about breast cancer and breast screening in the media or news makes you think about getting } \\
\text { a mammogram }\end{array}$ & 3.6 & 0.8 & 3.4 & 1.0 & 3.6 & 0.9 & 1.7 & 0.418 \\
\hline Reminder letters would help you to get a mammogram & 4.0 & 0.3 & 3.7 & 0.8 & 3.9 & 0.5 & 8.1 & $0.017^{*}$ \\
\hline Reminder phone calls or text messages would help you to get a mammogram & 4.0 & 0.3 & 3.7 & 0.8 & 3.9 & 0.5 & 8.1 & $0.017^{*}$ \\
\hline Routine educational talks regarding breast cancer awareness would help you to get a mammogram & 3.6 & 0.8 & 3.4 & 1.0 & 3.6 & 0.9 & 1.7 & 0.418 \\
\hline $\begin{array}{l}\text { You feel confident that if you had a mammogram done, any abnormalities in your breasts will be } \\
\text { detected }\end{array}$ & 3.7 & 0.6 & 3.5 & 0.7 & 3.7 & 0.6 & 3.1 & 0.378 \\
\hline You can arrange other things in your life to get a mammogram & 4.2 & 0.6 & 4.0 & 0.9 & 4.1 & 0.7 & 6.2 & 0.103 \\
\hline In case you need a mammogram, you will find a place to get it done & 4.2 & 0.5 & 4.1 & 0.5 & 4.2 & 0.5 & 3.3 & 0.355 \\
\hline You can make an appointment for a mammogram & 4.2 & 0.5 & 4.2 & 0.5 & 4.2 & 0.5 & 3.3 & 0.355 \\
\hline You can arrange transportation to get a mammogram & 4.2 & 0.5 & 4.2 & 0.5 & 4.2 & 0.5 & 3.3 & 0.355 \\
\hline You can talk to people at the breast screening centre about your concerns & 4.1 & 1.0 & $\mathrm{n} / \mathrm{a}$ & $\begin{array}{l}\mathrm{n} / \\
\mathrm{a}\end{array}$ & 4.1 & 1.0 & $\mathrm{n} / \mathrm{a}$ & $\mathrm{n} / \mathrm{a}$ \\
\hline You can find a way to pay for a mammogram if you need to & 4.3 & 0.4 & 4.2 & 0.5 & 4.2 & 0.5 & 2.9 & 0.234 \\
\hline
\end{tabular}

$R$ Reverse scored

*Significant at $a=0.05$

${ }^{a}$ Chi-square test was applied for all health beliefs; hence the categorical answers were used to apply this test for association. For each question, respondents were asked to select a number between 1 and 5 , where $1=$ strongly disagree and $5=$ strongly agree 
Table 3 Comparison of Illness Perceptions between attendees and non-attendees

\begin{tabular}{|c|c|c|c|c|c|c|c|c|}
\hline \multirow{2}{*}{$\begin{array}{l}\text { Attendance to the second breast screening invitation } \\
\text { Illness Perception }\end{array}$} & \multicolumn{2}{|l|}{ Yes } & \multirow{2}{*}{$\begin{array}{l}\text { No } \\
\text { Mean }\end{array}$} & \multicolumn{3}{|c|}{ Total } & \multicolumn{2}{|c|}{ Chi-Square test $^{\mathrm{a}}$} \\
\hline & Mean & SD & & SD & Mean & SD & $x^{2}$ & $p$-value \\
\hline The presence of a lump or thickening in the breast & 3.9 & 0.3 & 3.9 & 0.4 & 3.9 & 0.4 & 4.8 & 0.186 \\
\hline Nipple discharge & 3.9 & 0.4 & 3.8 & 0.4 & 3.9 & 0.4 & 0.8 & 0.666 \\
\hline Sudden nipple retraction & 3.8 & 0.4 & 3.7 & 0.5 & 3.8 & 0.4 & 1.3 & 0.509 \\
\hline Change in shape or appearance of the nipple & 3.9 & 0.3 & 3.8 & 0.4 & 3.9 & 0.3 & 1.0 & 0.603 \\
\hline Breast swelling, dimpling, redness or soreness of the skin & 3.9 & 0.3 & 3.7 & 0.5 & 3.9 & 0.4 & 4.2 & 0.124 \\
\hline Skin changes of the breast & 3.8 & 0.4 & 3.7 & 0.5 & 3.8 & 0.4 & 1.3 & 0.509 \\
\hline A sudden change in breast size & 3.9 & 0.4 & 3.8 & 0.4 & 3.9 & 0.4 & 3.4 & 0.180 \\
\hline Aching breasts & 3.6 & 0.6 & 3.4 & 0.6 & 3.6 & 0.6 & 4.1 & 0.132 \\
\hline Stress or worry & 2.9 & 0.9 & 2.8 & 0.8 & 2.9 & 0.9 & 0.8 & 0.673 \\
\hline Your mental attitude (e.g. thinking about life negatively) & 2.4 & 0.6 & 2.2 & 0.5 & 2.4 & 0.6 & 1.9 & 0.379 \\
\hline Family problems or worries & 2.9 & 0.9 & 2.7 & 0.8 & 2.8 & 0.9 & 1.5 & 0.477 \\
\hline Overwork & 2.4 & 0.7 & 2.2 & 0.6 & 2.4 & 0.7 & 1.5 & 0.483 \\
\hline Your emotional state (e.g. feeling down, lonely, anxious, empty) & 2.5 & 0.8 & 2.3 & 0.5 & 2.5 & 0.7 & 3.6 & 0.167 \\
\hline Your personality & 2.5 & 0.8 & 2.3 & 0.5 & 2.4 & 0.7 & 1.9 & 0.597 \\
\hline Hereditary - it runs in the family & 4.6 & 0.5 & 4.4 & 0.7 & 4.6 & 0.6 & 5.1 & 0.080 \\
\hline Diet or eating habits & 3.3 & 0.9 & 2.8 & 0.9 & 3.2 & 0.9 & 7.1 & 0.069 \\
\hline Poor medical care in the past & 3.3 & 0.9 & 3.3 & 0.8 & 3.3 & 0.9 & 0.9 & 0.818 \\
\hline Your own behaviour & 2.6 & 0.7 & 2.7 & 0.6 & 2.6 & 0.7 & 3.6 & 0.164 \\
\hline Ageing & 3.0 & 0.9 & 3.2 & 0.9 & 3.1 & 0.9 & 1.2 & 0.562 \\
\hline Smoking & 3.7 & 0.6 & 3.5 & 0.8 & 3.7 & 0.7 & 3.5 & 0.174 \\
\hline Alcohol & 3.5 & 0.8 & 3.2 & 0.9 & 3.4 & 0.8 & 2.6 & 0.272 \\
\hline A germ or virus & 3.1 & 0.8 & 3.0 & 0.8 & 3.1 & 0.8 & 0.8 & 0.686 \\
\hline Pollution in the environment & 3.7 & 0.7 & 3.3 & 1.0 & 3.6 & 0.8 & 6.2 & 0.104 \\
\hline Altered immunity & 3.6 & 0.7 & 3.8 & 0.5 & 3.7 & 0.6 & 5.7 & 0.129 \\
\hline Chance or bad luck & 2.9 & 1.0 & 3.1 & 1.0 & 2.9 & 1.0 & 4.1 & 0.386 \\
\hline Accident or injury & 3.0 & 1.0 & 3.0 & 0.9 & 3.0 & 0.9 & 0.9 & 0.831 \\
\hline Breast cancer will last a short time & 2.7 & 0.7 & 2.7 & 0.5 & 2.7 & 0.7 & 3.8 & 0.286 \\
\hline Breast cancer is likely to be permanent rather than temporary & 3.4 & 0.7 & 3.2 & 0.8 & 3.3 & 0.7 & 3.4 & 0.178 \\
\hline A patient with breast cancer goes through cycles in which her illness gets better and worse & 3.6 & 0.7 & 3.4 & 0.7 & 3.5 & 0.7 & 3.0 & 0.394 \\
\hline Breast cancer has major consequences on a patient's life & 4.4 & 0.6 & 4.1 & 0.6 & 4.3 & 0.6 & 6.3 & 0.096 \\
\hline Breast cancer will not have much effect on your life & 1.5 & 0.7 & 1.5 & 0.8 & 1.5 & 0.7 & 3.7 & 0.297 \\
\hline Breast cancer would strongly affect the way others see you & 3.4 & 0.9 & 3.6 & 0.8 & 3.5 & 0.8 & 1.4 & 0.506 \\
\hline Breast cancer has serious economic and financial consequences & 3.9 & 0.5 & 3.8 & 0.5 & 3.9 & 0.5 & 1.9 & 0.587 \\
\hline Breast cancer would strongly affect the way you see yourself as a person & 4.1 & 0.5 & 4.1 & 0.6 & 4.1 & 0.5 & 0.6 & 0.736 \\
\hline Breast cancer would threaten a relationship with your husband or partner & 3.1 & 1.0 & 2.9 & 0.9 & 3.1 & 0.9 & 1.4 & 0.714 \\
\hline If you had breast cancer, your whole life would change & 4.4 & 0.6 & 4.0 & 0.4 & 4.3 & 0.6 & 11.2 & $0.011^{*}$ \\
\hline If you developed breast cancer, the chances of living a long life would decrease & 4.1 & 0.4 & 4.0 & 0.0 & 4.0 & 0.3 & 3.9 & 0.142 \\
\hline There is a lot which you can do to control the symptoms if Breast Cancer occurs & 3.9 & 0.5 & 4.0 & 0.0 & 3.9 & 0.4 & 1.8 & 0.604 \\
\hline The course of Breast Cancer will depend on your actions & 4.0 & 0.4 & 4.0 & 0.0 & 4.0 & 0.3 & 1.5 & 0.691 \\
\hline Your actions will have an effect on the outcome of Breast Cancer & 4.0 & 0.4 & 4.0 & 0.0 & 4.0 & 0.3 & 2.2 & 0.524 \\
\hline There is no treatment that will help to improve Breast Cancer & 2.1 & 0.6 & 2.0 & 0.6 & 2.0 & 0.6 & 0.5 & 0.930 \\
\hline The treatment provided will be effective in controlling or curing Breast Cancer & 4.0 & 0.2 & 4.0 & 0.2 & 4.0 & 0.2 & 0.4 & 0.804 \\
\hline The negative effects of Breast Cancer can be prevented or avoided by the treatme & 4.0 & 0.2 & 4.0 & 0.2 & 4.0 & 0.2 & 1.0 & 0.621 \\
\hline
\end{tabular}


Table 3 Comparison of Illness Perceptions between attendees and non-attendees (Continued)

\begin{tabular}{|c|c|c|c|c|c|c|c|c|}
\hline \multirow{2}{*}{$\begin{array}{l}\text { Attendance to the second breast screening invitation } \\
\text { Illness Perception }\end{array}$} & \multicolumn{2}{|l|}{ Yes } & \multirow{2}{*}{$\begin{array}{l}\text { No } \\
\text { Mean }\end{array}$} & \multicolumn{3}{|c|}{ Total } & \multicolumn{2}{|c|}{ Chi-Square test $^{\mathrm{a}}$} \\
\hline & Mean & SD & & SD & Mean & SD & $x^{2}$ & $p$-value \\
\hline You have a clear picture and understanding of Breast Cancer & 3.6 & 0.7 & 3.7 & 0.7 & 3.7 & 0.7 & 0.7 & 0.722 \\
\hline Breast Cancer is a mystery to you & 3.2 & 1.0 & 3.2 & 1.0 & 3.2 & 1.0 & 1.3 & 0.860 \\
\hline You get anxious when you think about Breast Cancer & 3.6 & 1.1 & 3.7 & 1.0 & 3.6 & 1.1 & 3.2 & 0.359 \\
\hline Breast Cancer makes you feel afraid & 4.2 & 0.7 & 4.3 & 0.5 & 4.2 & 0.7 & 2.2 & 0.523 \\
\hline You get worried when you think about Breast Cancer & 4.3 & 0.8 & 4.4 & 0.5 & 4.3 & 0.7 & 2.3 & 0.504 \\
\hline
\end{tabular}

*Significant at $a=0.05$

${ }^{a}$ Chi-square test was applied for all illness perceptions; hence the categorical answers were used to apply this test for association. For each question, respondents were asked to select a number between 1 and 5 , where $1=$ strongly disagree and $5=$ strongly agree

constructs 'causes of breast cancer' and 'consequences' from the model ( $p$-value slightly greater than 0.05$)$, the accuracy to predict non-attendance would decrease from 30.0 to $15.4 \%$ even though $p>0.05$.

Although 'perceived barriers' remains the most important construct to describe the variance between attendees and non-attendees, illness perception constructs (breast cancer identity, its causes and consequences) can also be considered as strong predictors of second BS uptake; a result further echoed in Model 5, where the predictors are all related to illness perceptions (breast cancer identity and consequences). Hence, although Health Beliefs are important predictors of BS uptake, the model accuracy improved with the inclusion of illness perception items into one logistic regression model (Model 6 vs Model 3).

\section{Predicting attendance to second screening using first screening uptake}

When a logistic regression model was applied to predict second (subsequent) BS uptake using the first BS uptake as the predictor (Table 6, Model 8), non-attendance was predicted with an accuracy of $65.4 \%$ and attendance was predicted with an accuracy of $83.8 \%$.

Another model (Model 9) incorporated the Health Beliefs and Illness Perception constructs as covariates, together with the first screening uptake variable as the main independent variable. Model 9 shows that, following the inclusion of all the constructs, 'Perceived barriers' and 'Breast cancer identity' were found to be important covariates to improve the accuracy of predicting the attendance to the second screening cycle i.e. 83.8\% (Model 8) to $91.9 \%$ (Model 9). On the other hand, model accuracy dropped from 65.4\% (Model 8) to 61.5\% (Model 9)

Table 4 Comparisons between health beliefs/illness perception constructs and second breast screening uptake

\begin{tabular}{|c|c|c|c|c|c|}
\hline & Range & $\begin{array}{l}\text { Attendees } \\
(n=74)\end{array}$ & $\begin{array}{l}\text { Non-attendees } \\
(n=26)\end{array}$ & Test Statistic & $\overline{p \text {-value }}$ \\
\hline Perceived Susceptibility & $3-15$ & $M=9.5, S D=0.8$ & $M=9.6, S D=0.9$ & $1019.5^{b}$ & 0.626 \\
\hline Perceived Benefits & $6-30$ & $M=24.0, S D=1.7$ & $M=23.6, S D=1.6$ & $864.0^{\mathrm{b}}$ & 0.384 \\
\hline Perceived Barriers & $13-65$ & $M=27.0, S D=4.5$ & $M=29.2, S D=6.1$ & $-2.0^{a}$ & $0.049^{*}$ \\
\hline Cues to action & $7-35$ & $M=27.6, S D=2.8$ & $M=25.9, S D=4.4$ & $726.5^{b}$ & 0.061 \\
\hline Self-Efficacy & $7-35$ & $M=24.9, S D=2.7$ & $M=24.2, S D=2.7$ & $783.0^{\mathrm{b}}$ & 0.129 \\
\hline Breast Cancer Identity & $8-40$ & $M=30.8, S D=1.9$ & $M=29.9, S D=2.5$ & $776.0^{\mathrm{b}}$ & 0.124 \\
\hline Causes of Breast Cancer & $18-90$ & $M=55.8, S D=7.2$ & $M=53.9, S D=5.9$ & $1.2^{\mathrm{a}}$ & 0.238 \\
\hline Cancer Timeline: Acute/Chronic & $2-10$ & $M=6.1, S D=0.8$ & $M=5.9, S D=0.8$ & $839.0^{b}$ & 0.295 \\
\hline Cancer Timeline: Cyclical & $1-5$ & $M=3.6, S D=0.7$ & $M=3.4, S D=0.7$ & $829.5^{\mathrm{b}}$ & 0.221 \\
\hline Consequences & $8-40$ & $M=28.8, S D=2.3$ & $M=28.1, S D=1.9$ & $744.0^{\mathrm{b}}$ & 0.083 \\
\hline Personal Control & $3-15$ & $M=11.9, S D=0.7$ & $M=12.0, S D=0.0$ & $1014.0^{\mathrm{b}}$ & 0.432 \\
\hline Treatment Control & $3-15$ & $M=10.0, S D=0.6$ & $M=9.9, S D=0.6$ & $865.0^{\mathrm{b}}$ & 0.265 \\
\hline Illness Coherence & $2-10$ & $M=6.8, S D=1.2$ & $M=6.9, S D=1.1$ & $991.5^{b}$ & 0.802 \\
\hline Emotional Representations & $3-15$ & $M=12.1, S D=2.3$ & $M=12.4, S D=1.8$ & $991.5^{\mathrm{b}}$ & 0.811 \\
\hline
\end{tabular}

*Significant at $a=0.05$

a Independent Samples t-test

b Mann Whitney 
Table 5 Logistic Regression Models on second breast screening uptake against different variables and different constructs

\begin{tabular}{|c|c|c|c|c|c|c|c|c|}
\hline & B & SE & Wald & $P$-value & OR & $95 \% \mathrm{Cl}$ & $\begin{array}{l}\text { Model Accuracy } \\
\text { YES }\end{array}$ & $\begin{array}{l}\text { Model Accuracy } \\
\text { NO }\end{array}$ \\
\hline Model 1: Demographics & & & & & & & $100 \%$ & $0 \%$ \\
\hline Age & -0.154 & 0.084 & 3.329 & 0.068 & 0.858 & $0.727,1.011$ & & \\
\hline Constant & 7.926 & 4.905 & 2.611 & 0.106 & 2769.527 & & & \\
\hline Model 2: Health Status & & & & & & & $100 \%$ & $0 \%$ \\
\hline Breast condition & -1.093 & 0.526 & 4.315 & 0.038 & 0.335 & $0.119,0.940$ & & \\
\hline Constant & 0.893 & 0.940 & 0.902 & 0.342 & 2.441 & & & \\
\hline Model 3: Health Beliefs & & & & & & & $93.2 \%$ & $30.8 \%$ \\
\hline No possibility of getting breast cancer & 1.064 & 0.474 & 5.030 & 0.025 & 2.897 & $1.144,7.338$ & & \\
\hline Fear of unknown procedure ${ }^{a}$ & 0.563 & 0.388 & 2.102 & 0.147 & 1.755 & $0.820,3.756$ & & \\
\hline GP advice & -1.145 & 0.562 & 4.158 & 0.041 & 0.318 & $0.106,0.956$ & & \\
\hline Constant & 0.480 & 2.717 & 0.031 & 0.860 & 1.617 & & & \\
\hline Model 4: Illness Perceptions & & & & & & & $89.2 \%$ & $69.2 \%$ \\
\hline $\begin{array}{l}\text { Breast swelling, dimpling, redness or soreness } \\
\text { of the skin }\end{array}$ & -1.796 & 0.720 & 6.215 & 0.013 & 0.166 & $0.040,0.681$ & & \\
\hline Diet & -1.029 & 0.312 & 10.873 & 0.001 & 0.357 & $0.194,0.659$ & & \\
\hline Altered immunity & 1.462 & 0.568 & 6.610 & 0.010 & 4.313 & $1.415,3.141$ & & \\
\hline Whole life would change & -1.334 & 0.533 & 6.257 & 0.012 & 0.263 & $0.093,0.749$ & & \\
\hline Constant & 9.082 & 3.931 & 5.337 & 0.021 & 8796.855 & & & \\
\hline Model 5: Health Beliefs and IIIness Perceptions & & & & & & & $89.2 \%$ & $69.2 \%$ \\
\hline $\begin{array}{l}\text { Breast swelling, dimpling, redness or soreness } \\
\text { of the skin }\end{array}$ & -1.796 & 0.720 & 6.215 & 0.013 & 0.166 & $0.040,0.681$ & & \\
\hline Diet & -1.029 & 0.312 & 10.873 & 0.001 & 0.357 & $0.194,0.659$ & & \\
\hline Altered immunity & 1.462 & 0.568 & 6.610 & 0.010 & 4.313 & $1.415,3.141$ & & \\
\hline Whole life would change & -1.334 & 0.533 & 6.257 & 0.012 & 0.263 & $0.093,0.749$ & & \\
\hline Constant & 9.082 & 3.931 & 5.337 & 0.021 & 8796.855 & & & \\
\hline Model 6: Health Beliefs and IIIness Perceptions & & & & & & & $95.9 \%$ & $84.6 \%$ \\
\hline Early detection & 5.699 & 2.097 & 7.390 & 0.007 & 298.646 & $\begin{array}{l}\text { 4.904, } \\
18,187.040\end{array}$ & & \\
\hline If early detection, treatment not as bad ${ }^{b}$ & 12.267 & 7.293 & 2.830 & 0.093 & $\begin{array}{l}2.126 \times \\
10^{5}\end{array}$ & $\begin{array}{l}0.132,3.427 \times \\
10^{11}\end{array}$ & & \\
\hline $\begin{array}{l}\text { Having mammography decreases chances of } \\
\text { dying }^{\mathrm{b}}\end{array}$ & -8.890 & 6.724 & 1.748 & 0.186 & 0.000 & $0.000,72.821$ & & \\
\hline Fear of unknown procedure & 5.210 & 1.842 & 8.003 & 0.005 & 183.103 & $4.955,6765.914$ & & \\
\hline Unnecessary radiation & 4.471 & 1.655 & 7.301 & 0.007 & 87.419 & $3.414,2238.732$ & & \\
\hline $\begin{array}{l}\text { Breast swelling, dimpling, redness or soreness } \\
\text { of the skin }\end{array}$ & -8.961 & 3.119 & 8.252 & 0.004 & 0.000 & $0.000,0.058$ & & \\
\hline Personality & -5.566 & 2.295 & 5.885 & 0.015 & 0.004 & $0.000,0.343$ & & \\
\hline Diet & -5.558 & 1.946 & 8.160 & 0.004 & 0.004 & $0.000,0.175$ & & \\
\hline Germ or virus & -5.721 & 2.168 & 6.967 & 0.008 & 0.003 & $0.000,0.229$ & & \\
\hline Altered immunity & 8.217 & 2.860 & 8.254 & 0.004 & 3705.048 & $\begin{array}{l}13.620,1.008 \times \\
10^{6}\end{array}$ & & \\
\hline Breast cancer last short time & -2.623 & 1.042 & 6.340 & 0.012 & 0.073 & $0.009,0.559$ & & \\
\hline Affects the way others see you & 3.105 & 1.286 & 5.831 & 0.016 & 22.305 & $1.795,277.210$ & & \\
\hline Whole life would change & -9.738 & 3.266 & 8.888 & 0.003 & 0.000 & $0.000,0.036$ & & \\
\hline You get worried if breast cancer occurs & 2.444 & 1.199 & 4.159 & 0.041 & 11.521 & $1.100,120.694$ & & \\
\hline Constant & 14.947 & 26.502 & 0.318 & 0.573 & $3.102 \times$ & & & \\
\hline
\end{tabular}


Table 5 Logistic Regression Models on second breast screening uptake against different variables and different constructs (Continued)

\begin{tabular}{|c|c|c|c|c|c|c|c|c|}
\hline & B & SE & Wald & $P$-value & OR & $95 \% \mathrm{Cl}$ & $\begin{array}{l}\text { Model Accuracy } \\
\text { YES }\end{array}$ & $\begin{array}{l}\text { Model Accuracy } \\
\text { NO }\end{array}$ \\
\hline & & & & & $10^{6}$ & & & \\
\hline Model 7: The 14 constructs & & & & & & & $94.6 \%$ & $30.0 \%$ \\
\hline Perceived barriers & 0.155 & 0.054 & 8.305 & 0.004 & 0.167 & $1.051,1.296$ & & \\
\hline Breast cancer identity & -0.231 & 0.120 & 3.691 & 0.055 & 0.794 & $0.627,1.005$ & & \\
\hline Causes of breast cancer ${ }^{c}$ & -0.070 & 0.040 & 3.022 & 0.082 & 0.932 & $0.861,1.009$ & & \\
\hline Consequences $^{c}$ & -0.204 & 0.116 & 3.082 & 0.079 & 0.815 & $0.649,1.024$ & & \\
\hline Constant & 11.286 & 4.983 & 5.129 & 0.024 & $79,721.454$ & & & \\
\hline
\end{tabular}

$B$ Unstandardized coefficients, SE Standard error, OR Odds ratio, CI Confidence interval

${ }^{a}$ Fear of unknown procedure' was retained due to better accuracy in the logistic regression model. Without this variable, the accuracy would decrease from 30.8 to $19.2 \%$

'b'If early detection, treatment not bad' and 'Having mammography decreases death' were retained due to better accuracy in the logistic regression model. Without these variables, the accuracy would decrease from 84.6 to $76.9 \%$

${ }^{c}$ 'Causes of breast cancer' and 'Consequences' were retained due to better accuracy in the logistic regression model. Without these variables, the accuracy would decrease from 30.0 to $15.4 \%$

when predicting non-attendance to the second invitation at the MBSP.

\section{Discussion}

It is not enough to getting women to initiate BS, but it is essential to encourage them to maintain use over time. Previous studies have examined re-attendance rates $[6$, 16, 32]. However, BS statistics are not available specifically for a second BS invitation. The available routine BS statistics largely provide cross-sectional estimates of coverage rather than information on women's ongoing attendance at BS [33]. Moreover, data has long relied on self-reports [34], are measured by area deprivation (using either residential postcodes or general practice postcodes) rather than individual characteristics [35] and can be affected by inflation based on registered general practice lists [33].

Our preliminary rates for Maltese women invited to their subsequent call seem to be lower than those in other countries (Fig. 1: from the total data $(n=100)$, $62 \%$ of Maltese women attended the first and second round, 9\% had attended the first but not the second round, $17 \%$ attended neither call). In a recent study in
London among different ethnic groups [6], white British women were most likely to attend their first call (67\%) and routine recall (78\%). Mixed White and Asian women had the next highest uptake of routine recall invitations (75\%), followed by Indian women (first call (61\%) or routine recall (74\%) appointments), Pakistani (52 and 67\%, respectively) and Bangladeshi women (43 and $61 \%$, respectively). The lower subsequent uptake rates in Malta could be due to the programme being relatively new. However, we could not find previous studies that explored re-attendance. We therefore sought to explore the associations and predictive psychosocial factors to second screening based on social cognitive theory.

All sociodemographic characteristics were not significantly associated with second screening uptake and the latter were also found to be non-significant predictors of second screening to the MBSP. These findings are substantiated by similar predictors of returning to a second screen in Australia [16].

More specifically, earlier studies found that women with a breast problem were more likely to undergo clinical breast examination (CBE) and mammography than those

Table 6 Logistic regression analysis on the prediction of second breast screening uptake

\begin{tabular}{lllllllll}
\hline & B & SE & Wald & P-value & OR & $95 \%$ Cl & Model Accuracy YES & Model Accuracy NO \\
\hline $\begin{array}{l}\text { Model 8: 2nd Screening Uptake } \\
\text { 1st Screening Uptake }\end{array}$ & -2.278 & 0.519 & 19.266 & 0.000 & 0.102 & $0.037,0.283$ & & $65.4 \%$ \\
$\quad$ Constant & 0.348 & 0.377 & 0.853 & 0.356 & 1.417 & & & \\
Model 9: 2nd Screening Uptake & & & & & & & $91.9 \%$ & $61.5 \%$ \\
1st Screening Uptake & 2.462 & 0.571 & 18.591 & 0.000 & 11.728 & $3.830,35.914$ & & \\
Perceived barriers & 0.129 & 0.057 & 5.102 & 0.024 & 1.138 & $1.017,1.273$ & & \\
Breast cancer identity & -0.272 & 0.123 & 4.917 & 0.027 & 0.762 & $0.599,0.969$ & & \\
Constant & 0.157 & 3.730 & 0.002 & 0.966 & 1.170 & & & \\
\hline
\end{tabular}

$B$ Unstandardized coefficients, SE Standard error, OR Odds ratio, CI Confidence interval 
who had none [36, 37], while poor self-rated general health status was not associated with ever having had a mammogram in another study [38]. This relationship is likely driven by higher knowledge levels on the benefits of BS [36]. In contrast, we did not observe significant differences between attendees and non-attendees for self-reported health status in this study, except for those who claimed they had a breast condition. The latter women were more likely not to attend for second screening when compared with those who said they did not have any breast problem. We are aware that self-reports may not be as accurate as clinically documented mammographic reports. Nonetheless, in view of the nature and organization of the cognitive and emotional representations of such a health threat, as proposed by CSM $[8,26,27]$, women may have opted to attend for private mammography [4], possibly as our earlier study suggests, to obtain an earlier result [7]. Such reasons for non-attendance to second round screening merit further investigation in the local context.

This study also provides evidence that women who were less knowledgeable of the recommended screening frequency were less likely to reattend at the MBSP for a second invitation. There is a similar widespread lack of knowledge of the recommended screening guidelines for a first BS invitation in Malta [4] and in other countries $[39,40]$. The impact of the physician-patient relationship may be a reason for the latter finding. In this respect, it is important to note the variation in the order of invitation from service to service. For example, in the UK, women are invited to BS through GP practices [41] whereas in Malta, women are not registered with GP practices but are invited to BS according to age cohorts. Possibly, this infrequent encounter between GPs and Maltese women (Table 1) may be the reason for physicians' lack of opportunity to address knowledge gaps and to recommend regular $\mathrm{BS}$ practices.

Factors associated with BS behaviours in other populations $[42,43]$ were similar to the second BS round at the MBSP. Namely, Maltese women who believed that they were susceptible to $\mathrm{BC}$, considered the personal consequences of the disease, believed that mammography was not painful, and considered cues to action to motivate them to attend, were more likely than others to re-attend. Similarly, items for BC consequences and cues to action as well as mammography pain were also significantly associated with first BS uptake at the MBSP. Evidence has shown that women's responsibilities within the family may conflict with self-care and limit screening attendance and re-attendance [44]. Efforts to educate health care providers, particularly physicians, should emphasize the importance of mammography referral and regular physical check-ups [43].
Of the remaining cognitive variables, perceived $\mathrm{BC}$ susceptibility and attitude towards use predicted attendance to the second BS round, echoing predictors of repeat use in other studies [45] while contrasting other evidence [32]. Attitudes towards BS behaviour and risk perceptions may be necessary components of why Maltese women contemplate maintaining a behaviour, but may not be prime motivators to influence the initiation of that behaviour.

Self-efficacy was not significantly associated with maintaining BS practices in our study but played a key role in explaining why some women were unable to initiate BS at the MBSP [4]. Although previous research has shown that self-efficacy may be particularly central in moving women from contemplating about undergoing mammography to actually obtaining it [46], in the context of a second BS invitation, the rising challenges or barriers women experience when trying to maintain that behaviour may buffer the intentions that prompt planning for that behaviour [32].

Although several variables differentiated those women who returned for second round screening in the programme from those who did not, the 'perceived barrier' construct was found to consistently explain the differences between attendees and non-attendees and to improve the accuracy of predicting attendance to the second screening cycle; a concurrent finding for first invitation to the MBSP [8]. A trial by Farhadifar and colleagues [47] also suggests that regular BS practices are related to fewer barriers. The fact that some women did not return to their second invitation implies that based on their first contact with the screening service, they were less likely to return for routine calls. In the extant literature, this is attributable to a previous negative experience [48], possibly due to pain or discomfort [7, 49], embarrassment, distress, unhelpful staff and/or lower reassurance during the first screen [50]. Our national data also provides evidence that fear of pain was a major factor for not attending the first BS invitation [4] and similarly, this study found pain to be a significant determinant to non-adherence. Preparing women through the invitation letter or in screening campaigns [51] and improving the mammography experience so that it matches women's expectations could help to increase and maintain BS uptake [6].

The inclusion of both Health Beliefs and Illness Perception items in our study improved the accuracy of predicting non-attendance to the second cycle (Model 6, 84.6\%). This finding coincides with findings for first invitation [4]. Given the importance of both theories and the higher predictive accuracy for both BS cycles, it is likely that psychosocial variables, women's perception of $\mathrm{BC}$ and its related risk, and the enactment of cancer control measures predict regular BS behaviours [52] in 
an attempt to gain control over the disease [53]. This sense of internal control has been proven among disease-effected individuals across diverse health contexts $[22,54,55]$ and healthy individuals $[8,52]$.

Finally, when considering that only one variable was utilised to predict second screening uptake, Model 8 can be considered as an extreme improvement over all the previous logistic regression models (Table 5). Furthermore, the fact that Model 8 utilised only one predictor to predict second uptake makes the model more efficient and easy to use. Moreover, first screening uptake is a very important and significant predictor to predict future uptake as this variable does not require any health beliefs and/or illness perception variables or any other information to predict second BS uptake. Our results further support the evidence that women who obtain at least one mammogram are more likely to obtain subsequent screening $[8,12,56]$. Attendees may be more aware of the possibility for $\mathrm{BC}$ to occur, possibly because a $\mathrm{BC}$ threat $\mathrm{BC}$ identity, causes and consequences found as CSM predictors for a second BS invitation in this study), coupled by BS benefits, may have helped the individual to ascertain what factors pose barriers to BS attendance and adjust these in the first place. Therefore, what matters most is the social and psychological characteristics, health behaviours and attitudes which women bring to screening the first time, such as a positive attitude towards BS, its value, health behaviours and the belief that an individual would be able to overcome any obstacles to attendance $[8,56]$. The most important implication is that if women can be recruited successfully on the first occasion, they will probably stay in the programme. Hence, efforts could focus on identifying and encouraging attendance among women who have never participated in BS and who are reluctant or unsure to participate initially [14] because if women are persuaded to change their beliefs, attendance rates will increase and reattendance will become a matter of routine [17].

\section{Strengths and limitations}

Our study was not subject to response bias because figures for re-attendance were extracted from screening records. This study is one of a few to assess sociodemographic and attitudinal variables as predictors of adherence, but we found none that used initial predictors including $\mathrm{HBM}$ and CSM to explore the second BS round. There are some limitations in our research. The limited sample size to examine women's attendance to a second BS invitation may have reduced the representativeness of the sample. While the percentage of women by district or age was similar to that of the larger study [4], our findings may not be generalizable to the entire Maltese female population invited to their second screening. The characteristics of some women may have changed from first to second screening; this may have introduced misclassification and an underestimation of the relationships presented. Notwithstanding, the study design was necessary for the feasibility to conduct a prospective study to clarify and strengthen our findings, based on an understanding of the culture and attitudes among the Maltese population. Additional research would help to identify barriers and reasons influencing decisions about $\mathrm{BS}$ maintenance at the MBSP.

\section{Conclusions}

Researchers have focused more often on promoting behaviour change than on sustaining change. We explored, for the first time, the psychosocial associations, differences and predictors to the second screening invitation based on demographic factors, health status, knowledge, health beliefs, illness perceptions, and actual previous health behaviours. The combination of HBM and CSM variables provided improved prediction of attendance and non-attendance to the second screening call. Perceived barriers, breast cancer identity, causes of $\mathrm{BC}$, and consequences contributed most to the regression models, though perceived barriers was consistently significant across the analyses. Interventions should particularly target non-attendance to first screening. If non-attendees can be persuaded to attend once, they are likely to re-attend, unless their screening experience has been a negative one. The implications of these results are considered for theory, policy and practice to improve the limited understanding of second round screening and to aid the design of culturally sensitive interventions to improve breast screening uptake in Malta.

\section{Abbreviations}

B: Unstandardized coefficients; BC: Breast cancer; BS: Breast screening; CHBMS-MS: Champion's Health Belief Model Scale for Mammography Screening; Cl: Confidence interval; CSM: Common Sense Model; GP: General practitioner; HBM: Health Belief Model; IPQ-R: Revised IIIness Perception Questionnaire; M: Mean score; MBSP: Maltese Breast Screening Programme; OR: Odds ratio; SD: Standard deviation; SE: Standard error

\section{Acknowledgements \\ The authors would like to forward their gratitude to Prof. Victoria Champion and Prof. Rona Moss-Morris for developing the CHBMS-MS and IPQ-R scales respectively and for providing the opportunity to translate and adapt it into the Maltese culture and language. This study was developed as part of the activities of the PhD in Health offered by the University of Stirling, Scotland. We thank the National Screening Programme in Malta for providing access to the data.}

\section{Funding}

The PhD program is part-financed by the Malta Government Scholarship Scheme (MGSS), Government of Malta. The main author (DM) would like to thank the MGSS for the financial support provided during her PhD studies. DM was supported by a grant (MGSS Contract MEDE 96/2012/25) that covered the yearly fees to the University of Stirling. The remaining studentship and running costs for this study were self-funded by DM. 


\section{Availability of data and materials}

Data supporting the conclusions of this study are included within the manuscript. The raw datasets analysed during the current study are available from the corresponding author on reasonable request.

\section{Authors' contributions}

DM conceived the study, supervised all aspects of its conduction and wrote the manuscript. VM assisted with data analysis and interpretation of data and revised the manuscript. GH assisted with the study design, and critically reviewed and revised the manuscript. All authors helped to conceptualise ideas, interpret findings and review drafts of the manuscript. All authors read and approved the final manuscript.

\section{Ethics approval and consent to participate}

Ethics approvals were obtained from the School Research Ethics Committee at the University of Stirling (SREC14/15-Paper No.18v4) and from the Maltese Health Ethics Committee (HEC 02/2015). Both ethics boards approved the use of verbal consent. Written permission was obtained from the Chief Executive Officer so that data could be computer generated from the MBSP register. Participants were informed that their data could be used for further analysis of subsequent BS cycles, if required, for which they provided verbal consent. Participants provided verbal consent over the telephone. The research assistant documented this manually in paper format by ticking Yes/No according to the participant's response.

\section{Consent for publication}

Not applicable.

\section{Competing interests}

The authors declare that they have no competing interests.

\section{Publisher's Note}

Springer Nature remains neutral with regard to jurisdictional claims in published maps and institutional affiliations.

\section{Author details}

'Faculty of Health Sciences, University of Stirling, School of Health Sciences, Room E9, Pathfoot, Stirling FK9 4LA, Scotland. ${ }^{2}$ Cancer Care Pathways Directorate, Sir Anthony Mamo Oncology Centre, Level -1, Dun Karm Street, Msida MSD 2090, Malta. ${ }^{3}$ Department of Management, University of Malta, Msida, Malta. ${ }^{4}$ Highland Campus, Centre for Health Science, Old Perth Road, Inverness IV2 3JH, UK.

Received: 10 February 2018 Accepted: 1 February 2019

Published online: 13 February 2019

\section{References}

1. Altobelli E, Lattanzi A. Breast cancer in European Union: an update of screening programmes as of March 2014 (review). Int J Oncol. 2014;45(5): 1785-92. https://doi.org/10.3892/ijo.2014.2632.

2. Greif J. Mammographic screening for breast cancer: an invited review of the benefits and costs. Breast. 2010;19:268-72.

3. Perry N, Broeders M, de Wolf C, Tornberg S, Holland R, von Karsa L, et al, editors. European guidelines for quality assurance in breast cancer screening and diagnosis. 4th ed. Luxembourg: Office for Official Publications of the European Communities; 2006.

4. Marmarà D, Marmarà V, Hubbard G. Health beliefs, illness perceptions and determinants of breast screening uptake in Malta: a cross-sectional survey. BMC Public Health. 2017;17:416. https://doi.org/10.1186/s12889-017-4324-6.

5. Ministry for Health, Malta. The National Cancer Plan for the Maltese Islands 2017-2021. Consultation Document, March 2017. https://socialdialogue.gov. mt/en/Public_Consultations/MEH-HEALTH/Documents/MinistryForHealthCancer\%20Plan.pdf. Accessed 7 Mar 2017.

6. Jack RH, Møller H, Robson T, Davies EA. Breast cancer screening uptake among women from different ethnic groups in London: a population-based cohort study. BMJ Open. 2014;4:e005586. https://doi.org/10.1136/bmjopen2014-005586.

7. Marmarà DM, Curtis J, Marmarà VA. Women's satisfaction of the Maltese breast screening Programme: a cross-sectional survey. Malta Med J. 2015; 27(4):13-21.
8. Anagnostopoulos F, Dimitrakaki C, Fitzsimmons D, Potamianos G, Niakas D, Tountas Y. Health beliefs and illness perceptions as related to mammography uptake in randomly selected women in Greece. J Clin Psychol Med Settings. 2012;19:147-64.

9. Ritvo P, Edwards SA, Glendon G, Mirea L, Knight JA, Andrulis IL, et al. Beliefs about optimal age and screening frequency predict breast screening adherence in a prospective study of female relatives from the Ontario site of the breast Cancer family registry. BMC Public Health. 2012;12:518. https:// doi.org/10.1186/1471-2458-12-518.

10. Marshall G. A comparative study of re-attenders and non-re-attenders for second triennial National Breast Screening Programme appointments. J Public Health (Oxf). 1994;16(1):79-86.

11. Coyle C, Kinnear H, Rosato M, Mairs A, Hall C, O'Reilly D. Do women who intermittently attend breast screening differ from those who attend every invitation and those who never attend? J Med Screen. 2014;21(2):98-103. https://doi.org/10.1177/0969141314533677.

12. Allen J, Stoddard AM, Sorensen GC. Do social network characteristics predict mammography screening practices? Health Educ Behav. 2008;35(6):763-76.

13. Abbaszadeh A, Haghdoost AA, Taebi M, Kohan S. The relationship between women's health beliefs and their participation in screening mammography. Asian Pacific J Cancer Prev. 2007:8(4):471-5.

14. Cockburn J, Schofield P, White V, Hill D, Russel I. Predictors of returning for second round screening at a population based mammographic screening programme in Melbourne, Australia. J Epidemiol Community Health. 1997; 51(1):62-6.

15. Halabi S, Skinner CS, Samsa GP, Strigo TS, Crawford YS, Rimer BK. Factors associated with repeat mammography screening. J Fam Pract. 2000;49(12): 1104-12.

16. O'Byrne AM, Kavanagh AM, Ugoni A, Diver F. Predictors of non-attendance for second round mammography in an Australian mammographic screening programme. J Med Screen. 2000;7(4):190-4.

17. Rutter DR, Calnan M, Field S, Vaile MSB. Predicting reattendance in the second round of the UK National Breast Screening Programme: a prospective 3-year longitudinal analysis. Breast. 1997;6(3):120-5.

18. Huaman MA, Kamimura-Nishimura KI, Kanamori M, Siu A, Lescano AG. Validation of a susceptibility, benefits, and barrier scale for mammography screening among Peruvian women: a cross-sectional study. BMC Womens Health. 2011;11:54.

19. Tanner-Smith EE, Brown TN. Evaluating the health belief model: a critical review of studies predicting. Soc Theory Health. 2010;8(1):95-125. https:// doi.org/10.1057/sth.2009.23.

20. Jahanlou AS, Lotfizade M, Karami NA. A New behavioral model (health belief model combined with two fear models): design, evaluation and path analysis of the role of variables in maintaining behavior. InTech. 2013. doi. org: https://doi.org/10.5772/52966. Accessed 9 Sept 2016.

21. Moss-Morris R, Weinman J, Petrie KJ, Horne R, Cameron LD, Buick D. The revised illness perception questionnaire (IPQ-R). Psychol Health. 2002;17:1-16.

22. Petrak A. Factors influencing breast and cervical cancer control in ethnically diverse groups of women. 2013. http://hdl.handle.net/1959.14/305146. Accessed 25 Nov 2016.

23. Decruyenaere M, Evers-Kiebooms G, Welkenhuysen M, Denayer L, Claes E. Cognitive representations of breast cancer, emotional distress and preventive health behaviour: a theoretical perspective. Psychooncology. 2000;9(6):528-36.

24. Adachi K, Kitamura T, Ueno T. Psychosocial factors affecting the use of mammography testing for breast cancer susceptibility: an eight-month follow-up study in a middle-aged Japanese woman sample. Open J Med Psychol. 2013;2:158-65. https://doi.org/10.4236/ojmp.2013.24024 Accessed 23 Feb 2017.

25. Adachi K, Toyoda M, Kitamura T, Ueno T. Illness perceptions of breast Cancer in Japanese middle- and early old-aged women: psychometric properties of the brief illness perception questionnaire for use in diagnosing breast Cancer in Japan. British J Med \& Med Res. 2015;5(12):1491-501. https://doi.org/10.9734/BJMMR/2015/14404.

26. Baines T, Wittkowski A. A systematic review of the literature exploring illness perceptions in mental health utilising the self-regulation model. J Clin Psychol Med Settings. 2013;20(3):263-74.

27. Leventhal H, Brissette I, Leventhal EA. The common-sense model of self-regulation of health and illness. In: Cameron LD, Leventhal H, editors. The self-regulation of health and illness behavior. London: Routledge; 2003. p. 42-65. 
28. de Castro EK, Peuker AC, Lawrenz P, Figueiras MJ. Illness perception, knowledge and self-care about cervical Cancer. Psychology. 2015;28(3):4839. https://doi.org/10.1590/1678-7153.201528307.

29. Marmarà D, Marmarà V, Hubbard G. Maltese translation and adaptation of Champion's health belief model scale and the revised illness perception questionnaire for breast screening among Maltese women. J Nurs Meas. 2017;25(3):486-503.

30. Marmarà D, Marmarà V, Hubbard G. Lifetime utilization of mammography among Maltese women: a cross-sectional survey. BMC Public Health. 2018; 18:182. https://doi.org/10.1186/s12889-018-5093-6.

31. Marmarà D, Marmarà V, Hubbard G. A National Cross-Sectional Study of adherence to timely mammography use in Malta. BMC Cancer. 2018;18:346. https://doi.org/10.1186/s12885-018-4278-9.

32. Gierisch JM, Earp JA, Brewer NT, Rimer BK. Longitudinal predictors of nonadherence to maintenance of mammography. Cancer Epidemiol Biomark Prev. 2010;19(4):1103-11.

33. Moser K, Patnick J, Beral V. Inequalities in reported use of breast and cervical screening in Great Britain: analysis of cross sectional survey data. BMJ. 2009; 338:b2025. https://doi.org/10.1136/bmj.b2025.

34. Meissner HI, Breen N, Coyne C, Legler JM, Green DT, Edwards BK. Breast and cervical cancer screening interventions: an assessment of the literature. Cancer Epidemiol Biomark Prev. 1998;7:951-61.

35. Maheswaran R, Pearson T, Jordan H, Black D. Socioeconomic deprivation, travel distance, location of service, and uptake of breast cancer screening in north Derbyshire, UK. J Epidemiol Community Health. 2006;60:208-12.

36. Parsa P, Kandiah M. Predictors of adherence to clinical breast examination and mammography screening among Malaysian women. Asian Pacific J Cancer Prev. 2010;11:681-8.

37. Juon HS, Seo YJ, Kim MT. Breast and cervical cancer screening among Korean American elderly women. Eur J Oncol Nurs. 2002;6:228-35.

38. Achat H, Close G, Taylor R. Who has regular mammograms? Effects of knowledge, beliefs, socioeconomic status, and health-related factors. Prev Med. 2005;41:312-20.

39. Charkazi A, Samimi A, Razzaghi K, Kouchaki GM, Moodi M, Meirkarimi K, Kouchaki AM, Shahnazi H. Adherence to recommended breast Cancer screening in Iranian Turkmen women: the role of knowledge and beliefs. ISRN Prev Med. 2013. https://doi.org/10.5402/2013/581027 Accessed 15 Mar 2017.

40. Sadler GR, Ko CM, Cohn JA, White M, Weldon R, Wu P. Breast cancer knowledge, attitudes, and screening behaviors among African American women: the Black cosmetologists promoting health program. BMC Public Health. 2007;7:57. https://doi.org/10.1186/1471-2458-7-57.

41. Zelenyanszki C. Maximising screening attendance - a reference guide: North West London Cancer Network; 2009. https://www.nivel.nl/sites/default/files/ bestanden/Maximising\%20Screening\%20Attendance\%20\%20Electronic\%20version.pdf. Accessed 5 Jan 2017

42. Kim J, Lee SK, Lee J, Choi M-Y, Jung SP, Kim MK, et al. Breast Cancer screening knowledge and perceived health beliefs among immigrant women in Korea. J Breast Cancer. 2014;17(3):279-86. https://doi.org/10.4048/ jbc.2014.17.3.279.

43. Secginli S, Nahcivan N. Factors associated with breast cancer screening behaviours in a sample of Turkish women: a questionnaire survey. Int J Nurs Stud. 2006:43:161-71.

44. Haley E, Avery EJ, McMillan SJ. Developing breast health messages for women in rural populations. J Consum Aff. 2011;45:33-51.

45. Rauscher GH, Hawley ST, Earp JA. Baseline predictors of initiation vs. maintenance of regular mammography use among rural women. Prev Med. 2005:40:822-30

46. Menon U, Champion V, Monahan PO, Daggy J, Hui S, Skinner CS. Health belief model variables as predictors of progression in stage of mammography adoption. Am J Health Promot. 2007;21:255-61.

47. Farhadifar F, Molina Y, Taymoori P, Akhavan S. Mediators of repeat mammography in two tailored interventions for Iranian women. BMC Public Health. 2016;16:149. https://doi.org/10.1186/s12889-016-2808-4.

48. Parkington SR, Faine N, Nguyen MC, et al. Barriers to breast cancer screening in a managed care population. Manag Care. 2009;18:34-45.

49. Carney PA, Harwood BG, Weiss JE, Eliassen MS, Goodrich ME. Factors associated with interval adherence to mammography screening in a population-based sample of New Hampshire women. Cancer. 2002;95:219-27.

50. Myklebust AM, Seierstad T, Stranden E, Lerdal A. Level of satisfaction during mammography screening in relation to discomfort, service provided, level of pain and breast compression. Eur J Radiography. 2009;1:66-72.
51. Aro AR, de Koning HJ, Absetz P, Schreck M. Two distinct groups of nonattenders in an organized mammography screening program. Breast Cancer Res Treat. 2001;70(2):145-53.

52. Petrak A, Sherman KA, Fitness J. Validation of the Croatian and Lebanese revised illness perception questionnaires for healthy people (IPQ-RH). Eur J Cancer Care (Engl). 2015;24(3):355-66. https://doi.org/10.1111/ecc.12164.

53. Katapodi MC, Lee KA, Facione NC, Dodd MJ. Predictors of perceived breast cancer risk and the relation between perceived risk and breast cancer screening: a meta-analytic review. Prev Med. 2004;38(4):388-402.

54. Hill S, Dziedzic E, Thomas S, Baker SR, Croft P. The illness perceptions associated with health and behavioural outcomes in people with musculoskeletal hand problems: findings from the north Staffordshire osteoarthritis project (NorStOP). Rheumatology (Oxford). 2007;46(6):944-51. https://doi.org/10.1093/rheumatology/kem015.

55. Cabassa L, Lagomasino IT, Dwight-Johnson M, Hansen MC, Xie B. Measuring Latinos' perceptions of depression: a confirmatory factor analysis of the illness perception questionnaire. Cultur Divers Ethnic Minor Psychol. 2008;14(4):377-84. https://doi.org/10.1037/a0012820.

56. Moodi M, Rezaeian M, Mostafavi F, Sharifirad GR. Determinants of mammography screening behavior in Iranian women: a population-based study. J Res Med Sci. 2012;17(8):750-9.
Ready to submit your research? Choose BMC and benefit from:

- fast, convenient online submission

- thorough peer review by experienced researchers in your field

- rapid publication on acceptance

- support for research data, including large and complex data types

- gold Open Access which fosters wider collaboration and increased citations

- maximum visibility for your research: over $100 \mathrm{M}$ website views per year

At BMC, research is always in progress.

Learn more biomedcentral.com/submissions 